\title{
Impacts of natural pore-water and offshore aquifer chemistry on the operation and economics of some subsurface intakes types for SWRO plants
}

Thomas M. Missimer ${ }^{1 *}$, lan Watson ${ }^{2}$, Robert G. Maliva ${ }^{3}$, Noreddine Ghaffour ${ }^{4}$, Abdullah A. H. Dehwah ${ }^{4}$, John Woolschlager ${ }^{1}$, and Michael Hegy ${ }^{1}$

${ }^{1 *}$ Corresponding author, Florida Gulf Coast University, Emergent Technologies Institute, U. A. Whitaker College of Engineering, 16301 Innovation Lane, Fort Myers, FL 33913

${ }^{2}$ RosTek Associates, Inc., 16006 Langhorne Court, Tampa FL 33947USA

${ }^{3}$ WSP USA Inc., 1567 Hayley Lane, Suite 202, Fort Myers, FL 33907 USA

${ }^{4}$ King Abdullah University of Science and Technology (KAUST), Water Desalination and Reuse Center (WDRC), Biological and Environmental Science and Engineering (BESE), Thuwal 239556900, Saudi Arabia

\begin{abstract}
Horizontal and slant wells are being investigated as a means of obtaining feed water for seawater reverse osmosis (SWRO) desalination plants. These well types have been touted to produce higher quality seawater that will reduce the rate of membrane biofouling by removing algae, bacteria, transparent exopolymer particles, and other fractions of natural organic matter similar to onshore wells located on the beach. As these new well types are being considered for large-scale use, a careful evaluation of the biogeochemistry of seawater that occurs within the nearshore subsurface sediments is necessary to assess potential impacts to the SWRO process train. A high percentage of the coastlines of the world contain offshore sediments with seawater that is anoxic in nature with significant concentrations of hydrogen sulfide and dissolved organic matter, iron, manganese, and heavy metals. Where dissolved iron and/or manganese occur at concentrations greater than $1 \mathrm{mg} / \mathrm{L}$ in raw seawater, there can be problematical for direct treatment using the SWRO process. Membrane scaling and biofouling could become issues, which may necessitate pretreatment to reduce dissolved iron and manganese to acceptable concentrations prior to entry into the membrane process. The anoxic nature of the water could complicate the pretreatment process to remove the dissolved metals. Pretreatment requirements could significantly raise the capital and operational costs of SWRO negating the economic advantages of subsurface intakes. Six SWRO cost scenarios were evaluated to assess the impacts of slant wells on capital and operating costs based on the necessary to remove or not remove dissolved iron and manganese. The capital cost comparison of two open-ocean intake pretreatment systems to those in slant wells shows an increase of 6 to $20 \%$. The difference in operating costs can range from $19 \%$ lower to $15 \%$ higher depending on the pretreatment required.
\end{abstract}


Keywords: Seawater reverse osmosis, Subsurface intake, Pretreatment, Dissolved iron, Dissolved manganese

\section{Introduction}

One of the major operating challenges of seawater reserve osmosis (SWRO) desalination facilities is biofouling of the membranes [1-3]. While it is unlikely that membrane biofouling can ever be eliminated, the rate of biofouling can be controlled by using extensive pretreatment processes [4,5] designed to remove inorganic and organic particulates including algae, fineorganic solids, and bacteria; and semi-dissolved or dissolved organic matter, such as particulate and colloidal transparent exopolymer particles (TEP) and other sticky polysaccharides that occur mostly within the biopolymer fraction of natural organic matter (NOM) [6]. Many of the precursors to biofouling are also known to be effectively removed by using subsurface intakes, such as conventional vertical wells [7-11] and seabed galleries [12, 13].

Two relatively new subsurface intake types, horizontal wells of the Neodren ${ }^{\mathrm{TM}}$ design and angle wells (Fig. 1), are being installed that use horizontal technology that has some major design advantages in that there is no major infrastructure constructed on the beach, large numbers of wells can be constructed from a single point of origin, and high yields can be obtained from each installation (Fig. 2) [14, 15]. A key issue in the use of these horizontal well types is the initial and long-term chemistry of the seawater residing below the seabed. The chemistry of the aquifer water will change as pumping occurs and induces vertical movement of seawater through the seabed into the well screens. It is the purpose of this research to assess what geochemical conditions are known from numerous studies of interstitial water chemistry in continental shelf areas and from testing of angle wells in California [16] and the potential impacts on the long-term operation of the SWRO plants using this intake type. In addition, a series of four design scenarios were developed to assess the impacts of varying types of pretreatment on the capital and operating costs of SWRO based on real-world conditions.

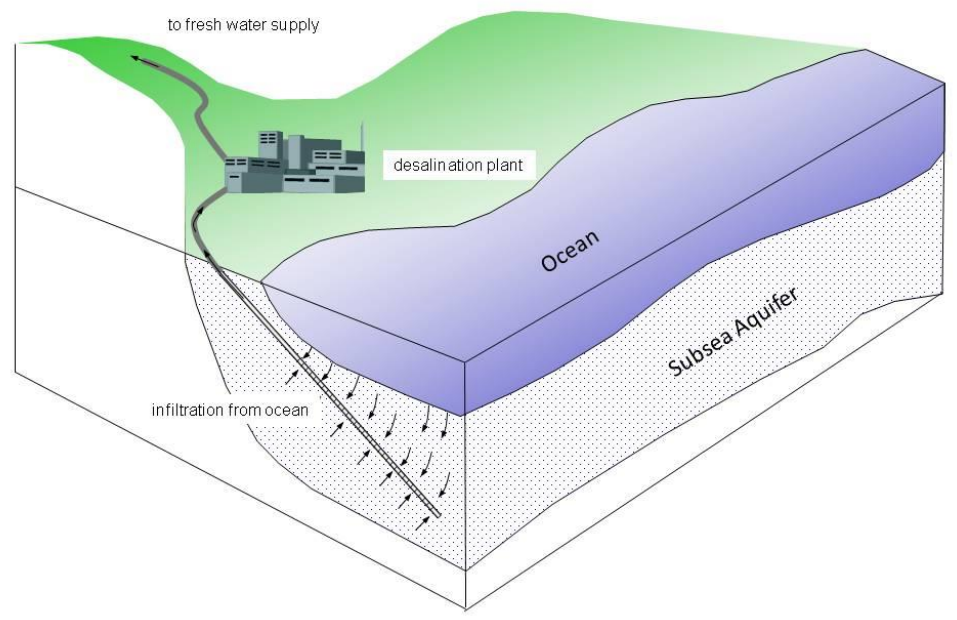

Figure 1. Conceptual diagram of a slant well (from Williams [16]) 


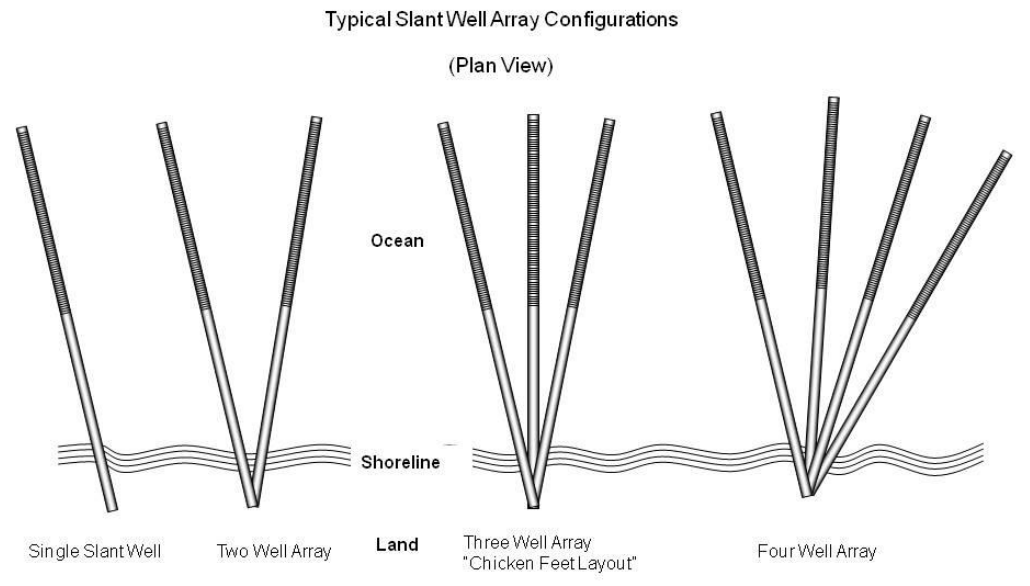

Figure 2. Use of a one or more slant wells from a single nearshore location (adapted from Williams [16])

2. Background on chemistry of seawater in nearshore marine sediments

The average iron concentration in seawater is about $2 \mu \mathrm{g} / \mathrm{kg}$ [17]. Iron is a biolimiting element in seawater in that it is necessary for life but present at very low concentrations [1820]. Algae growth is constrained by low iron concentrations and thus, the addition of dissolved iron can trigger algal blooms. Under oxic conditions, iron occurs in the very low solubility ferric (Fe ${ }^{+3}$; iron [III]) state. Dissolved iron when oxidized tends to precipitate out as amorphous or poorly crystalline iron (oxy)hydroxides.

In contrast to seawater, dissolved iron is ubiquitous in nearshore and continental shelf sediments and in fact, the seafloor sediments are a significant source of iron(III) in the world ocean [21-25]. Anoxic conditions occur in marine sediments between a few centimeters and about 2 meters below the seafloor in large areas of the continental shelf and in estuaries throughout the world. For example, the U.S. National Park Service constructed subsea monitoring wells at six sites in a 25-km transect off Miami-Dade County, Florida. Well clusters included sites in Biscayne Bay, barrier islands, and within and seaward of the reef tract. The shallow subsea groundwater was greatly depleted in dissolved oxygen relative to the overlying surface waters. Surface waters were generally near saturation with respect to oxygen, whereas groundwater was only at a fraction of saturation, nearing only 2 to $3 \%$ in a few samples [26]. The thickness of the oxic zone within marine sediments is controlled by the oxygen concentration in the overlying seawater column, the vertical hydraulic conductivity of the sediment, the ease of tidal-pumping wherein diffusion of oxygen can occur, the quantity of organic matter within the sediments, and the chemical oxygen demand of the interstitial seawater.

Under anoxic conditions, iron occurs predominantly in the relative soluble ferrous $\left(\mathrm{Fe}^{+2}\right.$; iron[II] state. Anoxic conditions allow dissolved iron(II) to remain soluble and not become 
precipitation as iron (oxy)hydroxides [27]. Reductive dissolution of iron-containing minerals or iron (oxy)hydroxide coatings on grains can release iron and other metals to solution. Anoxic conditions are maintained long-term due to the presence and decay of organic matter within the sediments and the inability of oxygen to diffuse to great depths below the sedimentseawater interface. Along with dissolved iron(II), high concentrations of manganese can also occur within the shallow and deep marine sediments [28].

Initial testing of slant wells tapping a sand aquifer containing seawater off the coast of Dana Point, California showed that dissolved iron and manganese occurred in concentrations ranging from 2.03 to $2.22 \mathrm{mg} / \mathrm{L}$ and 2.29 to $2.52 \mathrm{mg} / \mathrm{L}$, respectively [29]. Based on known subsurface geochemical conditions on the continental shelf, the reservoir of dissolved iron and probably dissolved manganese as well, are unlikely to be depleted by short-term pumping or perhaps ever.

\section{Operation of horizontal and slant wells}

Pumping of seawater from horizontal and slant wells tends to induce vertical movement of seawater through the seabed toward the screened-section of the wells (Fig. 1). However, the impacts on the water quality within the subsurface production zones can vary greatly between the two well types.

In horizontal well systems, the screen depth is generally closer to the seabed compared to an angle well. As seawater is pumped from the horizontal well, the induced recharge to the aquifer contains dissolved oxygen (DO) that will tend to move the redox front deeper in the aquifer with time. The initial seawater pumped from the horizontal well will be anoxic and will tend to transition to containing DO with time. Therefore, the initial concentrations of dissolved iron will likely be high due to the initial anoxic state of the water, but as DO migrates deeper into the aquifer, the iron will be removed through oxidation and precipitation as an iron (oxy)hydroxide phase. Therefore, high dissolved iron concentration is likely to be temporary.

However, if hydrogen sulfide in present the aquifer (i.e., sulfate reducing conditions develop), mixing of waters with different redox states could occur within a well if there are differences in the depth of the well screen below the seabed or the vertical hydraulic conductivity of the overlying sediments. The mixing of oxygenated seawater with seawater containing hydrogen sulfide could cause the precipitation of elemental sulfide of a very fine crystal size which will clog the cartridge filters and bypass the cartridge filters entirely to foul the membranes. The mixing of waters containing dissolved ferrous iron and dissolved oxygen could also cause the precipitation of iron (oxy)hydroxides which could also clog the well, and foul cartridge filters and membranes. The mixing of water with different redox states could be temporary or permanent depending on the distribution of hydraulic conductivities of the marine sediments, the hydraulic design of the well intake screens, and the interstitial water quality within the sediments.

In slant wells, the screens occur at a greater depth in the coastal aquifer compared to horizontal wells. Pumping of the wells produces a more radial inflow pattern [16] and the inducement of vertical flow of water from the ocean into the overlying sediments would occur at a slower rate and may not change redox conditions within the aquifer near the well screens. Therefore, changes in the chemistry of the production aquifer may be slow or not occur within 
the lifetime of the well system. The initial dissolved iron and manganese concentrations measured may persist indefinitely into the future and require pretreatment to remove them prior to entry into the membrane process or significant scaling and/or fouling could occur. The water is also expected to remain anoxic and will likely contain hydrogen sulfide during the full system operational life. The hydrogen sulfide will have to be removed during post-treatment before the potable water can enter the distribution system.

Clogging due to iron and element sulfur precipitation can also occur in systems using conventional vertical beach wells if the wells produce from parts of an aquifer containing waters with different redox states. Iron clogging may occur, for example, if different chemically reduced waters are mixed with shallowed, oxic groundwater. There have been a few examples of this issue.

\section{Methods}

It is well known that the use of subsurface intake systems tends to reduce the cost of SWRO pretreatment, leading to an overall reduction in the cost of potable water production $[6,30]$. An analysis was made to assess the capital and operating costs of a SWRO desalination plant with a capacity of $100,000 \mathrm{~m}^{3} / \mathrm{d}$ using a slant well intake with six comparative scenarios. The first two design scenarios provide a baseline cases for conventional SWRO plants using an openocean intake system with full pretreatment. The third scenario assumes that the intake is a slant well which produces high quality seawater that requires minimal pretreatment similar to beach well systems. The fourth scenario assumes that the slant well intake produces seawater that will require the removal of dissolved iron under anoxic conditions (dissolved iron and manganese occurred in concentrations ranging from 2.03 to $2.22 \mathrm{mg} / \mathrm{L}$ and 2.29 to $2.52 \mathrm{mg} / \mathrm{L}$ ). The fifth scenario assumes that the slant well intake produces seawater that will require special pretreatment for dissolved manganese only with co-existing hydrogen sulfide. The sixth scenario assumes that both dissolved iron and manganese must be removed in the presence of hydrogen sulfide. The capital and operating costs for a 100,000 $\mathrm{m}^{3} / \mathrm{d}$ SWRO facility with a conventional intake and pretreatment system was taken from Ghaffour et al. [31]. The seawater produced from the slant wells was assumed to be anoxic with hydrogen sulfide at above $1 \mathrm{ppm}$. The cost to construct slant wells was considered as a ratio to the full facility cost, but not using only California construction costs. These costs were estimated using the literature, interviews with SWRO facility operators, and personal design experience.

\section{Results}

\subsection{Redox conditions and the long-term water quality issues requiring pretreatment}

Higher concentrations of iron and manganese in water pumped from slant wells requires that a careful evaluation of the water chemistry be conducted to evaluate the necessity of removal during pretreatment based on the potential for membrane scaling/fouling. The total concentrations and redox state of the metals, and the oxidation state of the seawater within the marine sediments are important factors in this analysis. 
Initially, the dissolved iron in the feed water from a slant well will be in an anoxic state, which would likely allow it to pass through the RO plant as ferrous iron, provided the transfer system is not open to the ambient air at any location. If this condition persists, then additional pretreatment for removal of dissolved iron would not be required. It must be emphasized that the water pumped from the slant wells (or any other chemically reduced water) cannot at any time come in contact with DO or atmospheric oxygen, even during rapid sand filtration (Fig. 3c).

As slant wells are operated, it is intended that surface seawater will be drawn into and through the aquifer that is penetrated by well screens, which will tend to increase the DO concentration in the sediments and interstitial water. Also, the differing depth between the seabed and the top of the slant well screens could cause oxygenated seawater to enter at the proximal end of the well to mix with anoxic seawater entering the well at the distal end. In this case, some oxidation of iron could take place during the transit of the seawater from the well to the treatment plant. The mixture of soluble ferrous and insoluble ferric iron will require that the well water be completely oxidized with iron removed before the water is fed into the RO membranes.

During water treatment oxidation of iron from the ferrous to the ferric state occurs fairly rapidly, but is influenced by a number of factors, including $\mathrm{pH}$, temperature, and ionic strength. Aeration will oxidize ferrous iron, but the reaction can be quite slow. Other oxidants, such as chlorine, ozone, chlorine dioxide and potassium permanganate react much more rapidly, and are feasible alternatives to air. However, given the trend away from the use of chlorine in seawater RO systems, the other options are preferred. If there is no significant concentration of organic matter in the seawater, the addition and removal of chlorine would not likely have any effect on biofouling of the membranes (Fig. 3d). If some iron scaling should occur, cleaning with citric acid is almost $100 \%$ effective in restoring flux. However, since it is not expected that in any of these systems the iron will be removed entirely from the sediments and produced seawater during the life of the plant, the iron treatment and removal system can be expected to be in operation for the entire useful life of the RO plant, and should be designed, operated and maintained with this in mind.

The presence of manganese in the manganous state presents a different challenge. Whereas ferrous iron can be readily oxidized by aeration with reasonably short reaction times, oxidation of manganous $\left(\mathrm{Mn}^{+2}\right)$ manganese to manganic $\left(\mathrm{Mn}^{+3}\right)$ manganese can take hours, or even days [32]. Some evidence exists to suggest that oxidation of the iron in the source water will not significantly impact the oxidation state of the manganese. If this is the case, manganic fouling of the membranes will not be an issue, since the RO concentrate containing the manganese will exit the treatment plant before membrane-damaging oxidation of the manganous ion occurs. [33].

If it is desirable to remove the manganese, for whatever reason, chlorine dioxide appears to be the most effective oxidant for manganese removal over a wide $\mathrm{pH}$ range. However, it is recommended that oxidation be avoided if possible, since the settleability and filterability of $\mathrm{Mn}^{+3}$ can be extremely challenging in routine treatment plant operations.

At locations where the slant-well water quality does not contain significant concentrations of iron or manganese but does contain relatively high concentrations of dissolved organic carbon (DOC), removal of the organic matter may not be necessary due to the lack of marine bacteria in the seawater that could initiate biofouling. In the case of a groundwater feed water 
source that contains high concentrations of DOC, it is unlikely that additional pretreatment would be necessary unless the metals are complexed with the dissolved organic compounds.

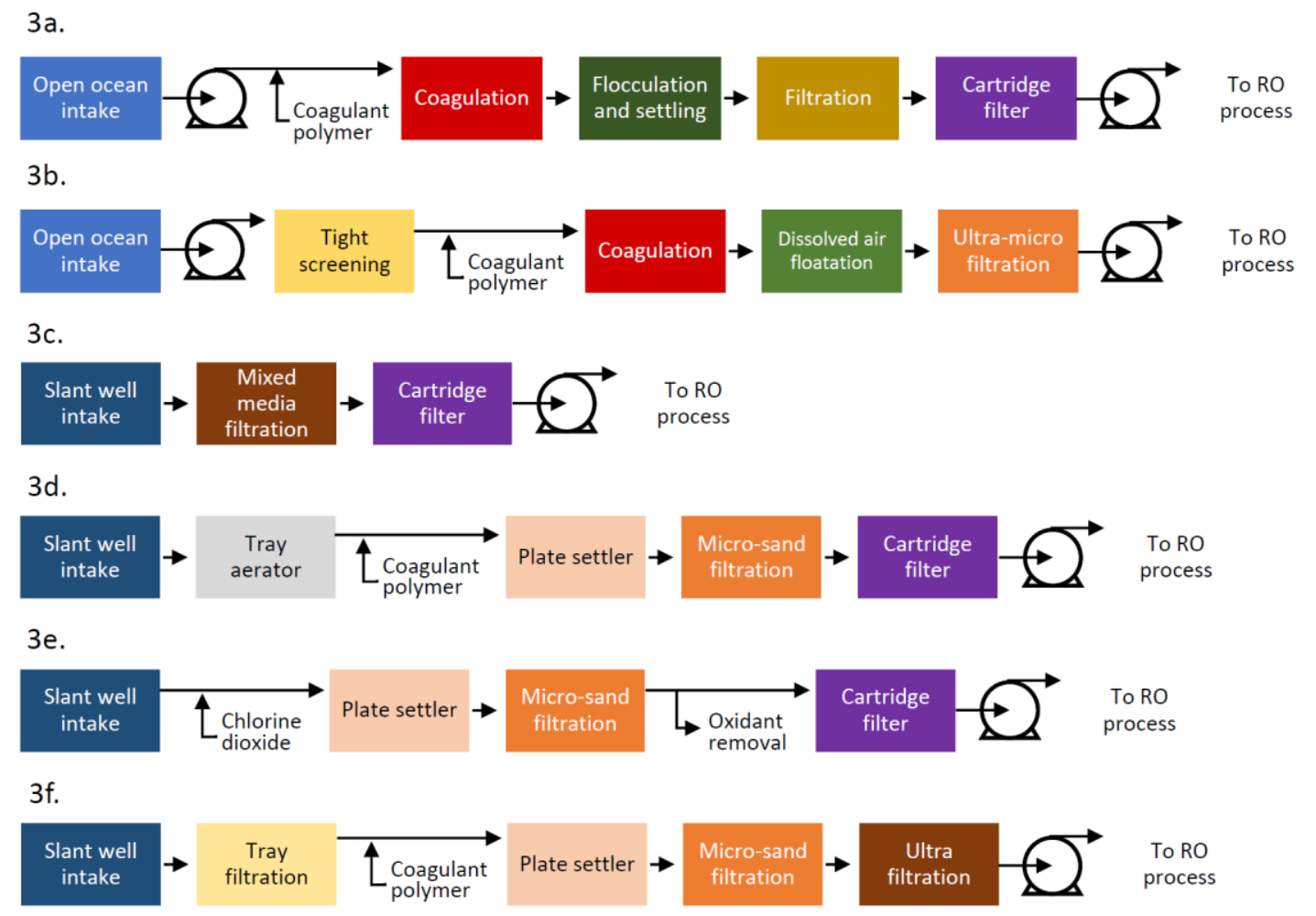

Figure 3. Comparative process diagrams for the pretreatment of a conventional seawater desalination system using an open-ocean intake versus a slant well intake with differing water chemistry issues. Note that cartridge filters are not shown following the UF/MF filtration in scenarios because it is not logical to place a 45 -micron filter after a 0.01 -micron filter.

In the case where the slant-well water yields both high concentrations of iron, manganese, and organic compounds complexed with them, the use of a chlorine/chlorine dioxide feed with dechlorination along with the addition of a coagulant and filtration could become necessary. This would tend to create the most operationally expensive pretreatment scenario.

Hydrogen sulfide, if it occurs, can take the form of a mixture of the soluble gas $\mathrm{H}_{2} \mathrm{~S}$ and the $\mathrm{HS}^{-}$ion. The distribution of the species is $\mathrm{pH}$ dependent, with a 50:50 split occurring at $\mathrm{pH}=7$. At the normal $\mathrm{pH}$ of seawater, virtually all of the $\mathrm{H}_{2} \mathrm{~S}(>80 \%)$ in the water will be in the form of $\mathrm{HS}^{-}$. The portion that is $\mathrm{H}_{2} \mathrm{~S}$ gas can be easily aerated with the iron and filtered with iron that has been oxidized to the insoluble ferric form.

5.2 Capital cost of treating the dissolved iron and/or manganese in presence of hydrogen sulfide 
The most practical way of oxidizing both the iron and $\mathrm{H}_{2} \mathrm{~S}$ is with a simple cascade tray aerator, followed by in-line coagulation, Lamella settling, and micro-sand filtration (Fig. $3 \mathrm{~d}$ ). Because the water is seawater, the materials of construction must be selected with care, to minimize repair and replacement. Redundant pumps should be provided, to allow on-line pump and electric motor maintenance. The pretreatment will also require the construction of a support system for collection and disposal of residuals from the settlers and the filter backwashing step. This will consist of a gravity thickener, and sludge handling facilities. Supernatant from the thickener can be returned to the head of the plant.

Most modern seawater RO plants today operate between 35 and 50 percent recovery. Assuming a $45 \%$ recovery design, the feedwater required for a $100,000 \mathrm{~m}^{3} /$ day facility would be $\sim 225,000 \mathrm{~m}^{3} /$ day. This capacity would be the design point for the pretreatment equipment.

An estimate of capital cost of the combined total plant with a slant well intake and the various pretreatment possibilities is shown in Table 1. Since the operating pressures for the pretreatment systems with iron and/or manganese removal are low, it is assumed that tanks and vessels will be fabricated from fiberglass reinforced polyvinylchloride (FRP), or as an alternative, fusion bonded epoxy-lined and coated steel. Pump wetted parts should be fabricated from duplex stainless steel. Piping should be fabricated from PVC and FRP as appropriate. There are a number of cost ratios for various pretreatment systems used in conventional SWRO systems that were used to develop the costs in Table 1. As the intensity of the pretreatment process train becomes larger, the foot-print of the facility also increases, thereby, increasing the total facility cost.

Table 1. Estimated capital and operating costs for a $100,000 \mathrm{~m}^{3} /$ day permeate capacity SWRO using the intakes and pretreatment scenarios given in Figure 3

\begin{tabular}{|c|c|c|}
\hline Scenario & $\begin{array}{c}\text { Estimated Capital Cost } \\
\text { US\$ }\end{array}$ & $\begin{array}{c}\text { Total Water Cost (per } \mathrm{m}^{3} \text { ) } \\
\text { US\$ }\end{array}$ \\
\hline $\begin{array}{c}\text { Standard SWRO plant using } \\
\text { surface intake system and } \\
\text { conventional pretreatment }\end{array}$ & $110,000,000^{\mathrm{a}}$ & $0.80^{\mathrm{a}}$ \\
\hline $\begin{array}{c}\text { Standard SWRO plant using } \\
\text { surface intake system with DAF } \\
\text { and MF/UF pretreatment }\end{array}$ & $130,000,000^{\mathrm{a}}$ & $1.00^{\mathrm{a}}$ \\
\hline $\begin{array}{c}\text { SWRO plant with a slant well } \\
\text { intake requiring pretreatment } \\
\text { typical of beach well intakes (no } \\
\text { pretreatment processes except } \\
\text { cartridge filters) }\end{array}$ & $115,000,000$ & 0.65 \\
\hline $\begin{array}{c}\text { SWRO plant using a slant well } \\
\text { intake with special treatment } \\
\text { for only dissolved iron }\end{array}$ & $140,000,000$ & 1.00 \\
\hline $\begin{array}{c}\text { SWRO plant using a slant well } \\
\text { intake with special treatment } \\
\text { for only dissolved manganese }\end{array}$ & $140,000,000$ & \\
\hline
\end{tabular}




\begin{tabular}{|c|c|c|}
\hline $\begin{array}{l}\text { SWRO plant using a slant well } \\
\text { intake with special } \\
\text { pretreatment for organic } \\
\text { compounds and dissolved iron } \\
\text { and/or manganese }\end{array}$ & $152,000,000$ & 1.15 \\
\hline
\end{tabular}

${ }^{a}$ Costs obtained from Ghaffour et al. [31]

\subsection{Impacts on SWRO operating costs}

The impact of the pretreatment system on the desalting facility operating and maintenance cost (O\&M) consists of chemical costs for coagulation, electric power, additional labor, and some possible residues disposal. The pretreatment will be largely automated, requiring primarily periodic visual checks on the operation, together with routine maintenance for pumps and motors, and sludge handling equipment. Probably one additional operator, and one additional maintenance technician would be required. Where ultrafiltration is used, periodic cleaning will be required. The estimated operating costs (OPEX) for all of the scenarios is given in Table 1.

\section{Discussion}

6.1 Comparison of a conventional SWRO plant aggregated intake and pretreatment capital cost/ of slant well intake cost on the overall capital cost of the facility

Traditionally, the pre-treatment of open-ocean intake-derived seawater prior to the RO process has consisted of straining and screening, flocculation/coagulation, settling, multi or dual media filtration and cartridge filtration. In recent years this approach has changed to a more site-specific approach, often utilizing drum filters, dissolved air flotation (DAF), and membrane filtration. In many cases chlorination of the raw seawater, either continuous or intermittent is practiced (intermittent is preferred), followed by dechlorination to prevent membrane damage. However, experience primarily in the Middle East has shown that continuous chlorination generates significant quantities of assimilable organic carbon (AOC), now known to be a major factor in the RO biofouling process [34]. Intermittent chlorination is now the norm.

Based on the literature, the capital cost for $100,000 \mathrm{~m}^{3} / \mathrm{d}$ capacity SWRO plant using surface seawater and a conventional pretreatment design can be itemized with $80 \%$ allocated to the treatment process and $20 \%$ for the pretreatment and intake aggregated [35, 36]. A survey conducted on some smaller capacity SWRO facilities located in Saudi Arabia along the Red Sea coast shows that facilities using well intakes with only dual-media pretreatment and cartridge filter have an allocated capital cost of $89 \%$ for the plant and $11 \%$ for the intake and pretreatment. One facility contained a specialized well intake design without dual-media filtration had the same cost ratio. Another facility using a well intake system with ultrafiltration (UF) pretreatment along with cartridge filters had a great ratio with the UF constituting $20 \%$ of the project cost alone with the wellfield in addition to it. In this case, the ratio was about $30 \%$ for the combined pretreatment and intake costs and $70 \%$ for the downstream plant. The new 
Monterey, California SWRO plant with a capacity of about $24,000 \mathrm{~m}^{3} / \mathrm{d}$ has a ratio of the slant well intake at $40 \%$ of total cost with the plant being $60 \%$ [37]. This does not include the pretreatment cost which may be an additional $14 \%$. Therefore, based on this background information, it is likely that the capital cost of a SWRO facility with a slant well intake system will be at least $20 \%$ greater than a conventional plant with a surface intake system. This is the case if a very small capital cost outlay is required for pretreatment, assuming the slant well produces seawater has a high quality and no additional pretreatment other than basic filtration is required. This would be similar to the Red Sea cases that have lower than average capital costs.

It is important to compare the capital cost of a conventional SWRO facility using an openocean intake to the same capacity system using a slant well intake system. Therefore, capital costs for two SWRO facilities that use open-ocean intake systems having different pretreatment trains have been developed based on average published costs for the baseline $100,000 \mathrm{~m}^{3} / \mathrm{d}$ permeate capacity $[31,35,36]$. The first example uses the addition of a coagulant polymer, coagulation, flocculation and settling, filtration, and then passage through a cartridge filter system before entering the RO process (Fig. 3a). The second system uses tight screening followed by coagulant polymer addition, coagulation, dissolved air floatation (DAF), micro/ultra-filtration and passage to the RO process (Fig. 3b). The capital cost estimates for these options are $\$ 118$ million and $\$ 130$ million respectively.

Use of a slant well intake provides a number of possible treatment challenges from those similar to using conventional well intakes to the requirement to remove dissolved iron, dissolved manages, dissolved iron and manganese, dissolved organics, and all three of these substances. Therefore, a series of pretreatment scenarios have been developed for comparison of these processes (Fig. 3). Since slant wells have higher construction costs compared to the average construction of conventional open-ocean intakes, all of the capital costs are higher than the baseline cost given in as scenario 3a (Fig. 3) of \$15 million with the exception of the open-ocean intakes SWRO plant using micro/ultra-filtration along with DAF which has an estimated $\$ 130$ million cost. Three of the pretreatment scenarios that allow removal of dissolved iron, manages, or organics all have a capital costs estimate of about $\$ 140$ million. The worst-case condition, where the removal of dissolved iron, manganese, and organics is required, the overall facility cost is the highest at $\$ 150$ million.

These cost estimates are based on global averages and the ratios found within these averages along with the only known slant well construction costs from California. However, it is known that California costs are quite high for overall SWRO facilities compared to global costs, so there may be some skewing of the intake costs when considering all of the capital costs.

6.2 Comparison of total water treatment costs of normal chemistry seawater from open intake to well type containing high dissolved iron concentration

The operating costs of SWRO is very dependent on the complexity of the pretreatment system. The lowest pretreatment costs have been found to occur on SWRO systems that use subsurface intakes that have minimal maintenance and require minimal pretreatment (sand filtration only) [6-10]. The average total water treatment costs for a $100,000 \mathrm{~m}^{3} /$ day permeate capacity SWRO system using an open-ocean intake ranges from about US\$0.80 to US\$1.00 per $\mathrm{m}^{3}$ (Table 1 ). 
The cost is based on the complexity of using a more conventional sand filtration pretreatment system versus membrane pretreatment and DAF which provides more operational security during harmful algal blooms [38].

The use of slant well intakes can have a wide range of impacts on the operating costs of a SWRO facility based on the chemistry of the feed water. At locations where the feed water does not create the necessary to add additional pretreatment processes, similar to many well intake systems used globally, the overall operating cost is low at $\$ 0.65 / \mathrm{m}^{3}$ or 10 to $35 \%$ lower than using an open-ocean intake based on differing pretreatment complexity. At locations, where dissolved iron or manganese or dissolved iron and manganese must be removed during pretreatment in the presence of hydrogen sulfide to prevent membrane scaling or fouling, the operational cost can be about equal to that of the "enhanced" pretreatment of open-ocean feed water at $\$ 1.00 / \mathrm{m}^{3}$. However, where very complex pretreatment would be required to remove several substances, the overall cost could rise to $\$ 1.15 / \mathrm{m}^{3}$ or $15 \%$ higher than enhanced pretreatment of open-ocean seawater (Table 1).

It is quite likely that SWRO facilities using slant well intakes will have to remove hydrogen sulfide either as part of pretreatment (Fig. 3d) or during post-treatment. Although there are some additional costs to remove the $\mathrm{H}_{2} \mathrm{~S}$, these costs may be offset by the lower rate of corrosion on the equipment operated in anoxic seawater conditions. The most corrosive seawater is that which has both high chloride concentration and dissolved oxygen. Therefore, the cost of post-treatment for $\mathrm{H}_{2} \mathrm{~S}$ removal was not considered.

\subsection{Long-term issue with aquifer containing dissolved iron and manganese and hydrogen sulfide}

Perhaps the most difficult issue with the use of slant well intakes is the uncertainty with regard to long-term water chemistry. The dissolved iron and/or manganese concentration may increase or decrease in time depending on the geochemical characteristics of the offshore aquifer, its hydraulic and geochemical heterogeneity, and well design. Water induced to infiltrate through the seabed will contain DO, which will be consumed as it flows through the seabed and aquifer sediments and rock. If all infiltrated water becomes entirely anoxic by the time it enters the well then no issue will occur in the feed water. Pretreatment challenges may arise if there is mixing of waters with different redox states, such as if oxygenated seawater enters the well near the proximal well section closest to the seabed and mixes with water drawn into the well from below and/or from the proximal (deepest) end of the well.

It has been predicted by some slant well designers that the reservoir of dissolved iron and manganese is limited and will be removed in time as normal seawater replaces it. However, the pretreatment design must take into consideration the seawater chemistry at the time of initial pumping. In the future, should the concentrations of problem metals become lower, then the complexity of the pretreatment processes could be simplified. Necessary for a conservative design will likely dictate that the process to remove the substances that could damage or foul the RO process will have to be constructed and operated until conditions permanently change in the feed water chemistry. A key issue is that long-term water chemistry cannot be predicted from relatively short-term testing, particularly when it may take a long-time for seawater that is induced to infiltrate to actually reach a well. 


\section{Conclusions}

Subsurface intakes have been used to provide a high degree of pretreatment analogous to conventional pretreatment systems in SWRO desalination. However, slant- or angle-well systems are a relatively new intake type with only test data available with no long-term operational data. Initial testing in California (USA) indicates that the feed water produced from these wells can contain high concentrations of dissolved iron and/or manganese. Also, the feed water tends to be anoxic and contains hydrogen sulfide. As long as the dissolved iron and manganese remains in the reduced state and there is no exposure of the feed water to oxygen, it should pass through the SWRO membranes without causing scaling or fouling. However, if the dissolved iron is partially oxidized, which can occur within the slant wells, then the coexisting ferrous iron and iron oxide must be removed in the pretreatment to prevent scaling or particulate clogging. Added degrees of pretreatment to remove dissolved iron and/or manganese in the presence of hydrogen sulfide adds to both to the capital and operating costs.

Comparison of the capital costs of a $100,000 \mathrm{~m}^{3} /$ day permeate capacity SWRO plant using open-ocean intakes and two different pretreatment methods were made to SWRO plants using slant-well intakes systems having four different feed water quality scenarios requiring varied pretreatment train designs. The CAPEX (capital) costs for the open-ocean intakes SWRO facilities was US\$110 and US\$130 million. The CAPEX costs for the slant well intake facilities were US\$118 to US\$150 million. In all cases the slant-well intake system costs more than a conventional open-ocean take system.

The total water treatment cost comparison shows a great deal of variability. The lowest total cost is US\$0.65/ $\mathrm{m}^{3}$ using a slant well intake with only sand filtration for pretreatment. The open-ocean intake facilities had total water treatment costs of US\$0.80 and US\$1.00/ $\mathrm{m}^{3}$ based on whether the pretreatment systems used DAF and MF/UF or conventional multimedia filters. Where slant wells are used that require dissolved iron or manganese removal, the total water treatment cost was the same as using an open-ocean intake system with DAF and membrane pretreatment or US\$1.00/ $\mathrm{m}^{3}$. If both dissolved iron and manganese had to be removed along with complexed organics, then the total water treatment cost using a slant well intake would be US\$1.15/m³.

When using these estimates, it is important to understand that the costs are based on global average numbers and could be higher or lower in different geographic regions, but the relative ratios should be equivalent. Also, slant well intake systems would be able to operate even during the worst oceanographic conditions, such as during harmful algal blooms. This would not be the case using the open-ocean intake pretreatment scheme utilizing solely sand filtration and may impact the systems using DAF and membrane pretreatment. Therefore, there is perhaps a greater degree of operational security using the slant well intake if the maintenance can be effectively performed. It is important to also recognize that the decision to utilize slant wells and other subsurface intakes may be driven by environmental and regulatory considerations rather than economics.

\section{References}


[1] H.-C. Fleming, G. Schaule, T. Greibe, J. Schmitt, and A. Tamachkiarowa, Biofouling the Achilles heel of membrane processes, Desalination 113 (2) (1997) 215-225.

[2] H. S. Vrouwenvelder, J. A. M. van Passen, H. C. Folmer, J. A. M. H. Hofman, and M. M. Nederlof, Biofouling of membranes for drinking water production, Desalination, 118 (1-3) (1998) 157-166.

[3] A. Matin, Z. Khan, S. M. J. Zaidi, and M. C. Boyce, Biofouling in reverse osmosis membranes for seawater desalination: phenomena and prevention, Desalination, 281 (1) (2011) 1-16.

[4] V. Bonnelye, M. A. Sanz, J. P. Durand, L. Plasse, F. Gueguen, and P. Mazounie, Reverse osmosis on open intake seawater: pre-treatment strategy, Desalination, 167 (2004) 191200.

[5] T. Nguyen, F. A. Roddick, and L. Fan, Biofouling of water treatment membranes: a review of the underlying causes, monitoring techniques, and control measures, Membranes 2 (2012) 804-840.

[6] S. Li, S.-T. Lee, S. Sinha, T. Leiknes, G.L Amy, N. Ghaffour, Transparent exopolymer particles (TEP) removal efficiency by a combination of coagulation and ultrafiltration to minimize SWRO membrane fouling, Water Research 102 (2016) 485-493.

[7] R. M. Rachman, S. Li, and T. M. Missimer, T. M., SWRO feed water quality improvement using subsurface intakes in Oman, Spain, Turks and Caicos Islands, and Saudi Arabia, Desalination 351 (2014) 88-100.

[8] A. H. A. Dehwah, S. Al-Mashharawi, N. Kammourie, and T. M. Missimer, T. M., 2015, Impact of well intake systems on bacterial, algae and organic carbon reduction in SWRO desalination systems, SAWACO, Jeddah, Saudi Arabia, Desalination and Water Treatment 55(10) (2015) 2594-2600.

[9] A. H. A. Dehwah, S. Li, S. Al-Mashharawi, H. Winters, and T. M. Missimer, Changes in feedwater organic matter concentrations based on intake type and pretreatment processes at SWRO facilities, Red Sea, Saudi Arabia, Desalination 360 (2015) 19-27.

[10] A. H. A. Dehwah, and T. M. Missimer, Subsurface intake systems: green choice for improving feed Seawater quality at SWRO desalination plants, Jeddah, Saudi Arabia: Water Research 88 (2016) 216-224.

[11] A. H. A Dehwah, S. Al-Mashharawi, K. C. Ng, and T. M. Missimer, Aquifer treatment of seawater to remove natural organic matter before desalination, Groundwater 55(3) (2017), p. 316-326.

[12] T. M. Missimer, A. H. A. Dehwah, L. Lujan, D. Mantilla, and S. Al-Mashharawi, Feasibility and design of seabed gallery intake systems along the Red Sea coast of Saudi Arabia with discussion of design criteria and methods, Chapter 11, in T. M. Missimer, B. Jones, and R. G. Maliva, editors, Intakes and outfalls for seawater reverse osmosis desalination facilities: Innovations and environmental impacts, Springer, Berlin, pp. 215-250, 2015.

[13] A. H. A. Dehwah, and T. M. Missimer, Seabed gallery intakes: Investigation of the water pretreatment effectiveness of the active layer using a long-term column experiment, Water Research 121 (2017) 95-108.

[14] T. Peters, D. Pinto', and E. Pinto', Improved seawater intake and pre-treatment system based on Neodren ${ }^{\mathrm{TM}}$ technology, Desalination 301(1-3) (2007) 134-140. 
[15] T. Peters, and D. Pinto', Seawater intake and partial pre-treatment with Neodren ${ }^{\mathrm{TM}}$ - results from investigation and long-term operation, Desalination and Water Treatment 24(1-3) (2010) 117-122.

[16] D. E. Williams, Slant well intake systems: design and operation, Chapter 14, In: T. M. Missimer, B. Jones and R. G. Maliva, eds., Intakes and Outfalls for Seawater ReverseOsmosis Desalination Facilities, Springer International Publishing, Switzerland, p. 275-320, 2015.

[17] J. I. Drever, The Geochemistry of Natural Waters. Prentice Hall, Englewood Cliffs N.J., 2018.

[18] F. M. M. Morel, J.G. Rueter, and N.M. Price, Iron nutrition of phytoplankton and its possible importance in the ecology of ocean regions with high nutrient and low biomass, Oceanography 4(2) (1991) 56-61.

[19] P. Boyd, J. LaRoche, M. Gall, R. Frew, and R. M. L. Mckay, Role of iron, light, and silicate in controlling algal biomass in subantarctic waters SE of New Zealand, Journal of Geophysical Research: Oceans 104(C6) (1999) 13395-13408.

[20] H. W. Ducklow, J. L. Oliver, and J. W. O. Smith, The role of iron as a limiting nutrient for marine plankton processes, In: J. Melillo, C. Field, and B. Moldan, eds. Interactions of the major biogeochemical cycles: global change and human impacts. Island Press, Washington, D.C. USA, p. 295-310, 2003.

[21] D. E. Canfield, Reactive iron in marine sediments, Geochim. Cosmochim. Acta 53 (1989) 619-632).

[22] K. S. Johnson, F. P. Chavez, and G. E. Friederich, Continental-shelf sediments as a primary source of iron for coastal phytoplankton, Nature 398 (1999) 697-700.

[23] V. A. Elrod, The flux of iron from continental shelf sediments: a missing source for global budgets, Geophys. Res. Letters 31 (2004), doi: 10.1029/2004GL020216.

[24] M. E. Jones. J. S. Beckler, and M. Taillefert, The flux of soluble organic-iron (III) from sediments represents a source of stable iron (III) to estuarine waters and the continental shelf, Limnol. Oceanogr. 56 (2011) 1811-1823.

[25] A. T. DeChanvalon, E. Metzger, A. Mouret, J. Knoery, E. Geslin, and F. Meysman, Jr., Twodimensional mapping of iron release in marine sediments at the submillimetre scale, Marine Chemistry 191 (2017) 34-49.

[26] C. Reich, R. B. Haley, T. Hickey, and P. Swarzenski, Groundwater characterization and assessment of contaminants in marine areas of Biscayne National Park, Technical Report NPS/NRWRD/NRTR-2006/356), U.S. National Park Service, 2006.

[27] N. O. G. Jorgenson, The sulfur cycle of a coastal marine sediment (Limfjorden, Denmark), Limnology \& Oceanography 22 (1977) 814-832.

[28] S. E. Calvert, and T. F. Petersen, Sedimentary geochemistry of manganese: Implications for the environment of formation of manganiferous black shales, Economic Geology 91 (1996) 36-47.

[29] D. E. Williams, Results of drilling, construction, development, and testing of Dana Point Ocean Desalination Project test slant well, U.S. Bureau of Reclamation Desalination and Water Purification Research and Development Program Report No. 152, 2009.

[30] T. M. Missimer, R. G. Maliva, M. Thompson, W. S. Manahan, and K. P. Goodboy, Reduction of seawater reverse osmosis treatment costs by improvement of raw water quality: 
Innovative intake designs, The International Desalination \& Water Reuse Quarterly, 20(3) (2010) 12-22.

[31] N. Ghaffour, T. M. Missimer, and G. Amy, Technical review and evaluation of the economics of desalination: Current and future challenges for better supply sustainability, Desalination 309 (2013) 197-207.

[32] S. D. Faust, O. M. Aly, Chemistry of Water Treatment, $2^{\text {nd }}$ Edition. Lewis Publishers, Boca Raton, Florida, 1998.

[33] E. Kartinen, C. Martin, Solving Morro Bay's Seawater Reverse Osmosis Plant's Iron Problem" Desalination of Seawater and Brackish Water, Chapter 5. American Water Works Association, 2006.

[34] Applegate, L. E., C. W. Erkenbrecher, and H. Winters, New chloramine process to control aftergrowth and biofouling in Permasep ${ }^{\mathrm{TM}}$ B-10 RO surface seawater plants, Desalination 74 (1989) 51-67.

[35] The World Bank, Renewable Energy Desalination: An Emerging solution to close the water gap in the Middle East and North Africa, International Bank for Reconstruction and Development/The World Bank, Washington, D. C., 2013.

[36] Fichtner (Fichtner GmbH, Co. KG), DLR (Deutsches Zentrum fur Luftund Raumfahrt e.V.) MENA regional water outlook, Part II, Desalination using renewable energy, task 1 Desalination potential; Task 2 - Energy requirements; Task 3 - Concentrate management, Fichtner and DLR, http://www.dlr.de/tt/Portaldata/41/Resources.dokumenteinstitute/system/projects/MEN A REGIONAL WATER OUTLOOK.pdf, 2011.

[37] Water Desalination Report, SWRO draft EIR open for discussion, Water Desalination Report 54(14) (2018) 2-3.

[38] Amato, T., K.- S. Park, W. Kim, and T. Kim, SWRO pre-treatment design using high-rate dissolved air floatation including preliminary pilot-scale results, Desalination and Water Treatment 51(7-9) (2103) 1804-1816. 